\title{
Precipitation variability and trends in Ghana: An intercomparison of observational and reanalysis products
}

\author{
R. Manzanas - L. K. Amekudzi - K. Preko · S. Herrera · J. M. \\ Gutiérrez
}

Received: date / Accepted: date

\begin{abstract}
Inter-annual variability and trends of annual/seasonal precipitation totals in Ghana are analyzed considering different gridded observational (gaugeand/or satellite-based) and reanalysis products. A qualitycontrolled dataset formed by fourteen gauges from the Ghana Meteorological Agency (GMet) is used as reference for the period 1961-2010. Firstly, a good agreement is found between GMet and all the observational products in terms of variability, with better results for the gauge-based products - correlations in the range of 0.7-1.0 and nearly null biases - than for the satellitegauge merged and satellite-derived products. In contrast, reanalyses exhibit a very poor performance, with correlations below 0.4 and large biases in most of the cases. Secondly, a Mann-Kendall trend analysis is carried out. In most cases, GMet data reveal the existence of predominant decreasing (increasing) trends for the first (second) half of the period of study, 1961-1985 (1986-2010). Again, observational products are shown to reproduce well the observed trends - with worst results for purely satellite-derived data- whereas reanalyses lead in general to unrealistic stronger than observed trends, with contradictory results (opposite
\end{abstract}

R. Manzanas (凶) · J. M. Gutiérrez

Grupo de Meteorología, Instituto de Física de Cantabria, CSIC-Univ. de Cantabria, Avda. de los Castros, s/n, 39005,

Santander, Spain

E-mail: rmanzanas@ifca.unican.es

L. K. Amekudzi · K. Preko

Meteorology and Climate Science Unit, Dept. of Physics,

Kwame Nkrumah Univ. of Science and Technology (KNUST),

Kumasi, Ghana

S. Herrera

Grupo de Meteorología, Depto. de Matemática Aplicada y Ciencias de la Computación, Univ. de Cantabria, Avda. de los Castros, s/n, 39005, Santander, Spain signs for different reanalyses) in some cases. Similar inconsistencies are also found when analyzing trends of extreme precipitation indicators. Therefore, this study provides a warning concerning the use of reanalysis data as pseudo-observations in Ghana.

Keywords precipitation $\cdot$ Ghana $\cdot$ gridded observations · reanalysis · variability · trends $\cdot$ extremes indicators

\section{Introduction}

Understanding variability and trends of precipitation in Ghana is crucial for different socio-economic activities, such as agriculture (Ofori-Sarpong, 2001; Cooper et al., 2008) and hydroelectric power - the main source of energy in the country (Kunstmann and Jung, 2005).Several studies have analyzed rainfall trends in West Africa, identifying a downward tendency for the period 1970-2000 (see e.g. Nicholson et al., 2000; Djomou et al., 2009, and references therein). Consistently, other studies have also found a decrease in precipitation in Ghana for the period 1980-2000 (as compared to 1950-1970), especially notorious in the south (Owusu and Waylen, $2009,2013)$. However, seasonal and local varying results have been also reported over this region - this kind of analysis is particularly difficult in Ghana since different precipitation regimes coexist from the coast in the south to the Sahelian region in the north, yielding a complex spatial climate variability (Cooper et al., 2008).- For instance, Kunstmann and Jung (2005) found that total annual precipitation in the Volta catchment was increasing by $5 \%$ but extremely decreasing (up to $70 \%$ ) in April and Lacombe et al. (2012) observed no significant trends for annual rainfall in the period 1960-2005, but 
local varying results for spells and onset of the wet season. However, the use of different gauges in the previous studies hinders a comparative analysis of the results. Therefore, a detailed seasonal analysis of rainfall variability and trends from quality-controlled gauge data is still needed in Ghana.

Due to the lack of dense gauge networks, some studies have considered alternative gridded observational and reanalysis products to perform this kind of analysis over West Africa. For instance, Jury (2013) described climatic trends of several meteorological variables in sub-Saharan Africa using, among others, the NCEP reanalysis and gridded observations from the Global Precipitation Climate Center (GPCC) and from satellite estimates.

In this paper we analyze the inter-annual variability and trends of annual/seasonal precipitation totals in Ghana during the last fifty years (1961-2010). To this aim, we consider a quality-controlled network of fourteen gauges from the Ghana Meteorological Agency as reference and compare the results with those obtained from a set of alternative observational gridded - gaugeand/or satellite-derived - and reanalysis products. Our main goal is to look for signals of change in precipitation in the period of study and to assess the performance of the aforementioned products to reproduce such changes, identifying the most suitable ones for a reliable use in Ghana.

The paper is organized as follows: the data used are described in Sec. 2. The different rainfall regimes of Ghana are analyzed in Sec. 3. Results and discussion are presented through Sec. 4. Finally, conclusions are given in Sec. 5 .

\section{Data}

\subsection{Gauge Data}

Daily rainfall from fourteen gauges from the Ghana Meteorological Agency (hereafter GMet) was considered for the period of study 1961-2010. These stations have not suffered changes in location and present less than $2 \%$ of missing data in the whole period. Gauges are spread across country and cover the different existing rainfall regimes (Cooper et al., 2008). To account for this in the next sections, we grouped the fourteen gauges into the same four main agro-ecological zones that have been used in previous studies (Owusu and Waylen, 2009, 2013), which are homogeneous in terms of rainfall regimes. Gauges forming these zones - referred hereafter to as North, Transition, South and Coast - are marked in Fig. 1 in black, blue, green and red color, respectively.

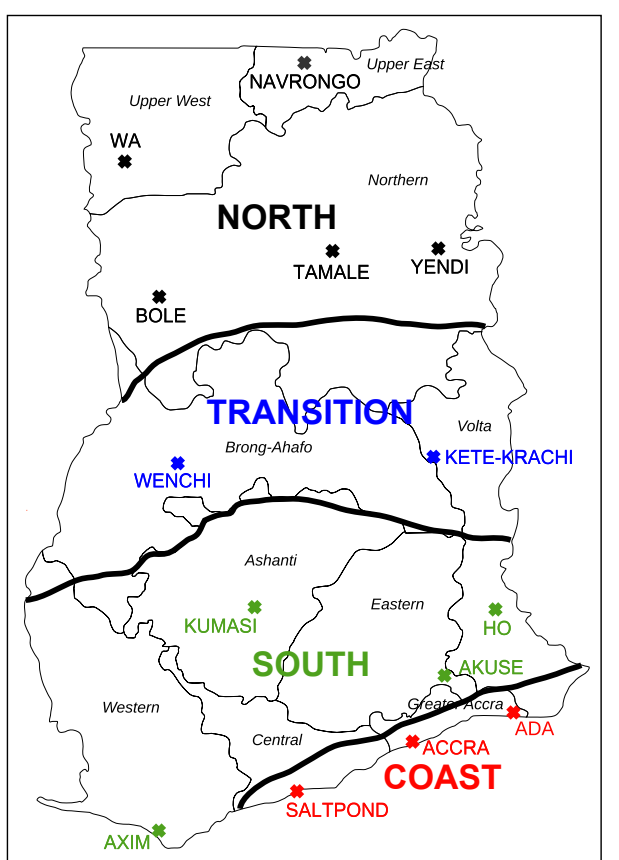

Fig. 1 Administrative map of Ghana showing the fourteen GMet gauges considered, grouped into the four main agro-ecological zones previously used in Owusu and Waylen (2009, 2013). Gauges belonging to the North/Transition/South/Coast zones are marked in black/blue/green/red.

\subsection{Gridded Observational Datasets}

To fully cover the wide variety of gridded observational products available nowadays, several gauge-based, satellitegauge merged and purely satellite-derived products were considered. With respect to the gauge-based products we have considered three datasets covering the full period of study 1961-2010: The Global Precipitation Climatology Centre Full Data Reanalysis version 6 (GPCC v6), the Climatic Research Unit Time-Series version 3.20 (CRU TS 3.20) and the PRECipitation reconstrucion over Land (PREC/L) from the NOAA. GPCC v6 provides monthly global land-surface precipitation on a regular grid at three spatial resolutions $\left(0.5^{\circ} \times 0.5^{\circ}\right.$ has been used here) for the period 1901-2010. This dataset is based on 67200 gauges worldwide and supports climate variability and historical trends analysis (Becker et al., 2013). CRU TS 3.20 provides monthly rainfall on a high-resolution $0.5^{\circ} \times 0.5^{\circ}$ global grid for the period 1901-2011 and allows for studying climate variations (Harris et al., 2013). PREC/L (Chen et al., 2002) provides monthly global precipitation totals from 1948 to 2013 at three spatial resolutions $\left(0.5^{\circ} \times 0.5^{\circ}\right.$ has been used here). Gauge observations come from over 17000 stations collected in the Global Historical Clima- 
tology Network version 2 (GHCND2) and the Climate Anomaly Monitoring System (CAMS) datasets.

With respect to the satellite-gauge merged products, two datasets were considered: The Global Precipitation Climatology Project version 2.2 (GPCP v2.2) and the CAMS-OPI. Note that although other combined datasets such as the CPC Merged Analysis of Precipitation (CMAP) and the African Rainfall Climatology version 2 (ARC2) exist, CMAP is comparable to GPCP v2.2 (Xie and Arkin, 1997) and ARC2 is consistent both with GPCP v2.2 and CMAP, with correlations of 0.86 (Novella and Thiaw, 2013). Thus, these two datasets have not been included in the study since no added value (with respect to GPCP v2.2) is expected to be obtained from them. GPCP v2.2 (Huffman et al., 1997) is a merged analysis that provides monthly mean precipitation on a $2.5^{\circ} \times 2.5^{\circ}$ global grid for the period 1979-2011. This dataset incorporates precipitation estimates from low-orbit satellite microwave data, geosynchronous-orbit satellite infra-red data and surface rain gauge observations. CAMS-OPI (Janowiak, 1999) combines satellite rainfall estimates from the Outgoing Longwave Radiation (OLR) Precipitation Index (OPI) with ground-based rain gauge observations from the Climate Anomaly Monitoring System (CAMS), providing monthly precipitation on a $2.5^{\circ} \times$ $2.5^{\circ}$ global grid from 1979 to present.

Finally, one purely satellite-derived dataset, the African Rainfall Climatology And Time-series dataset (TARCAT v2.0), was also considered. TARCAT v2.0 (Tarnavsky et al., 2013; Maidment et al., 2013) is a new dataset developed by the Tropical Applicatons of Meteorology using SATellite data and ground-based observations (TAMSAT) research group at the University of Reading. TARCAT v2.0 provides precipitation estimates at three temporal resolutions (monthly values have been used here) on a regular grid of approximately $4 \mathrm{~km}$ resolution over Africa from 1983 to present. Note that although other satellite datasets exist, all of them are either too short (series of less than 10 years) or temporally inhomogeneous (different sensors and different proportions of gauge data included at different times). Thus, TARCAT v2.0 is the only suitable option for our study. Furthermore, good results have been shown across most of Africa for this dataset (Tarnavsky et al., 2013) since the major part of the African rainfall is convective and TARCAT v2.0 is based on locally calibrated cold cloud duration derived entirely from Meteosat Thermal Infra-Red (TIR) imagery.

\subsection{Reanalysis Data}

Among the different atmospheric reanalyses currently available, only two of them cover the full period of study 1961-2010: The NCEP/NCAR Reanalysis I (NCEP v1) and the NOAA-CIRES 20th Century Reanalysis version 2 (20CR v2). The NCEP v1 (Kalnay et al., 1996) follows a 3D-var assimilation scheme whilst the 20CR v2 (Compo et al., 2011) uses the Ensemble Kalman Filter technique to produce an estimate of the complete state of the atmosphere and the uncertainty in that estimate. Therefore, considering both allows for assessing the differences between distinct generations of reanalyses. NCEP v1 $\left(20 \mathrm{CR}\right.$ v2) uses a $1.875^{\circ} \times 1.875^{\circ}$ $\left(2^{\circ} \times 2^{\circ}\right)$ grid and spans the period 1948 to present (1871-2010). Apart from NCEP v1 and 20CR v2, all reanalyses except ERA-40 (Uppala et al., 2005) start in 1979, with the beginning of the satellite era. From this year onward, up to five different reanalyses are available. However, all of them except the ERA-Int (Dee et al., 2011) follow a 3D-var assimilation scheme. Therefore, we opted for including ERA-Int and its predecessor ERA-40 (which use a 4D- and 3D-var assimilation scheme, respectively) in the study. ERA-40 (ERA-Int) provides precipitation on a $1.125^{\circ} \times 1.125^{\circ}\left(0.75^{\circ} \times\right.$ $0.75^{\circ}$ ) global grid for the period 1957-2002 (1979 to present). Daily accumulated precipitation - as computed from their different base resolutions - was considered for the above reanalyses.

Moreover, all the aforementioned gridded products, observational and reanalysis, were bi-linearly interpolated to the fourteen GMet gauges shown in Fig. 1. All the calculations were also done considering the alternative nearest grid-box interpolation scheme, obtaining very similar conclusions. Therefore, only results for the former interpolation technique are shown.

\section{Rainfall Regimes in Ghana}

Ghana presents different rainfall regimes along the country from the coast in the south to the Sahelian region in north (Cooper et al., 2008). These regimes are mainly defined by the north- and south-ward movement of the Inter-Tropical Convergence Zone (ITCZ) (Sultan and Janicot, 2003), which brings the African monsoon, giving rise to the uni- and bi-modal distribution characteristic of the northern and southern part of the country, respectively. Fig. 2 shows the climograms of monthly and seasonal accumulated precipitation for the four zones considered in the period of study.

As can be seen, the annual cycle in the North zone is characterized by a uni-modal distribution; one rainy season followed by a long dry season. In this region, 


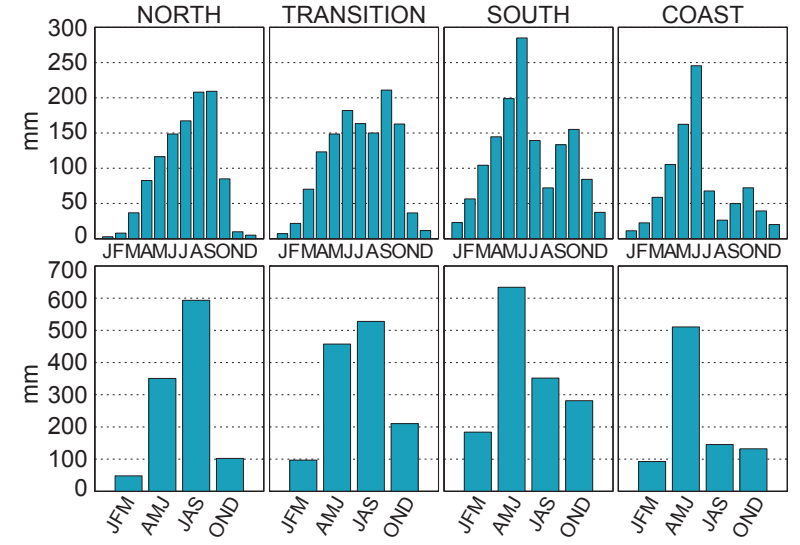

Fig. 2 Monthly and seasonal (first and second row, respectively) climograms showing the mean accumulated precipitation in the four zones for the period of study 1961-2010.

rainfall builds up gradually from small rains in April and reaches its maximum in August-September, when the rain-bearing tropical maritime air mass gets to the area. The decline of the rains is faster, with retreat dates at the end of October. Then, the dry northeast trade winds begin to dominate, resulting in the so called Harmattan season, which lasts from November until early March.

The Transition zone exhibits a longer rainy season which starts around April and reaches a relatively low maximum in June, which is almost maintained until September (maximum peak). This zone represents an interface between the uni- and bi-modal distributions.

The South and the Coast zones present the bi-modal distribution characteristic of the southern part of the country. In both, the onset of the monsoon occurs around April and the maximum rains (main peak) are reached in June, when the maritime tropical air mass is heavily charged with water vapor, what results in substantial rainfalls. Additionally, there is also a relatively short minor season (secondary peak) around October, when the ITCZ still lies on the West African mainland near the coast. Despite their similar annual cycles, rains in the Coast are lower than in the South, especially during the minor season, what can be attributed to a complex series of coastal/oceanic and atmospheric interactions (Acheampong, 1982).

\section{Results and Discussion}

All the results shown in this section have been calculated from inter-annual time-series of annual/seasonal precipitation values. These aggregated values have been calculated from the daily values available for the gauge observation from GMet and for the reanalysis products and from the monthly values available for the observational gridded datasets.

\subsection{Performance of Gridded Products}

The performance of the gridded (observational and reanalysis) products described in Sec. 2 was evaluated in terms of the Pearson correlation and bias - the latter in units of inter-annual observed standard deviationswith respect to GMet for their common period 19832000 (Fig. 3). The comparison was performed both at an annual and seasonal scale, considering the corresponding annual/seasonal accumulated precipitation series.

With regard to the gridded observations, gauge-based products show the best agreement with GMet. In particular, GPCC v6 shows the highest — around 0.9 in all cases - correlations and nearly null biases. CRU TS 3.20 performs also very well, with correlations around 0.8 in most cases and biases near to zero. PREC/L shows the poorest performance among the gauge-based datasets, with correlations around 0.6 and biases below 0.5. Concerning the satellite-gauge merged products, GPCP v2.2 provides slightly better correlations — with values in the range of 0.5-0.7 - than CAMS-OPI. Both present small (below 0.5) biases. Finally, the purely satellite-derived dataset, TARCAT v2.0, is shown to be comparable to the satellite-gauge combined products, providing similar correlations but slightly larger (negative) biases.

All the reanalysis products exhibit weak correlations (below 0.4 in most of the cases) and large biases there is a rather general dry/wet bias dipole over the northern/southern part of the country. - These results highlight the limitations of reanalysis data to undertake climate variability studies over the region of study. Among the four reanalyses, ERA-Int shows the highest correlations in all cases, whereas the other three exhibit a similar overall performance.

\subsection{Trends of Annual/Seasonal Precipitation Totals}

Inter-annual trends for the annual/seasonal accumulated precipitation series were calculated applying linear regression analysis. Moreover, the non-parametric two-sided Mann-Kendall test was applied to test the significance of the resulting trends. Since no significant auto-correlation was found for the target series, the original method without correction for auto-correlation was applied. Note that the same approach has been used in several studies to examine rainfall trends from gauge data across the globe (see e.g. van Belle and 

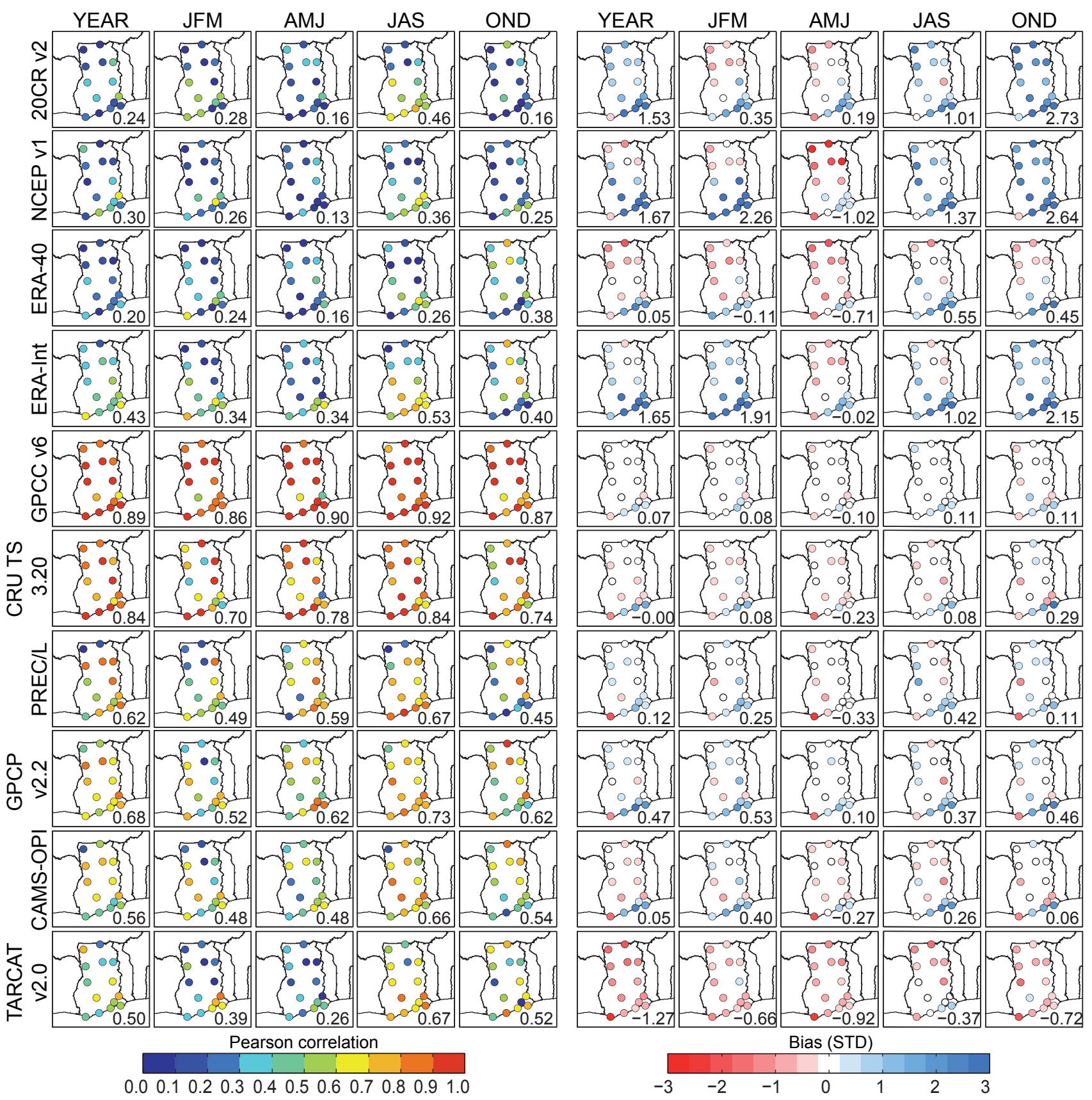

Fig. 3 Left: Pearson correlation between GMet and the different gridded products considered for the inter-annual time-series of annual/seasonal precipitation totals in the overlapping period 1983-2000. Right: As left but for the biases (in units of inter-annual observed standard deviations). The numbers inside each panel indicate the corresponding spatial averages.

Hughes, 1984; Zhang et al., 2001; Burn and Hag Elnur, 2002; Partal and Kahya, 2006; Obot et al., 2010).

In order to account for changing trends in precipitation, calculations were independently performed for the first and second half of the period of study (19611985 and 1986-2010) - hereafter referred to as P1 and $\mathrm{P} 2$, respectively.- These two periods were chosen after a careful analysis of the trends exhibited by the four datasets covering the whole period (GMet, NCEP v1, $20 \mathrm{CR}$ v2 and GPCC v6). In particular, Fig. 4 shows that the NCEP dataset exhibits significant decreasing (increasing) trends in most of the regions for P1 (P2), whereas the rest of datasets (including GMet) present - with only a few exceptions - no significant trends. Moreover, to test the robustness of the results to the choice of the cut-off year (1985-1986), alternative cut- 
offs in the range 1980-1990 were considered (note that some of the products start around 1980, with the beginning of the satellite era, so the period P2 is constrained to start from 1980 onwards). The obtained results were very similar in all cases.
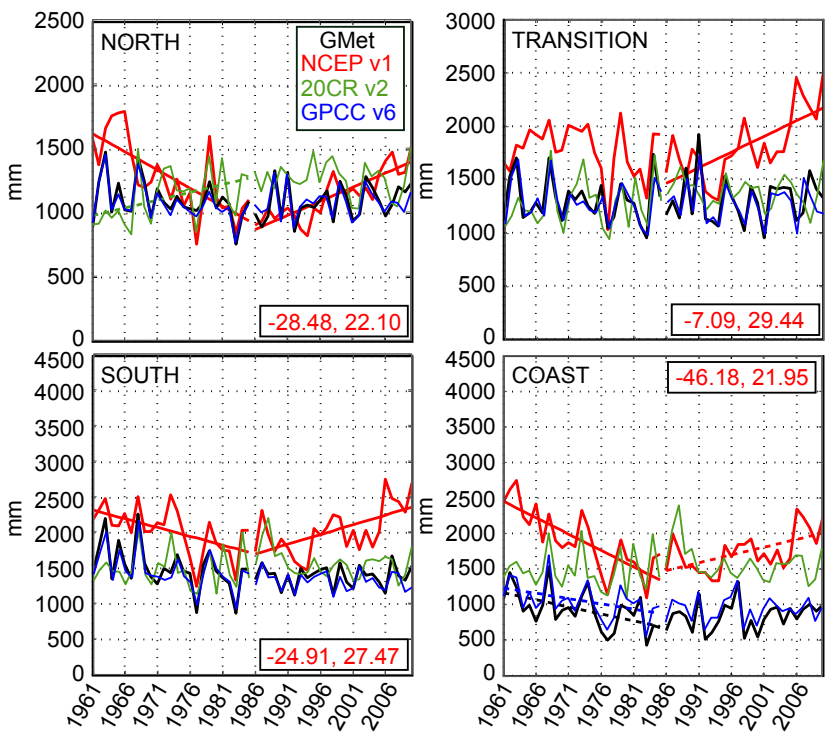

Fig. 4 Inter-annual time-series of annual precipitation totals for GMet (black), NCEP v1 (red), 20CR v2 (green) and GPCC v6 (blue), averaged in the four zones considered. Linear trends were independently calculated for P1: 1961-1985 and P2: 1986-2010 and are indicated in the different panels for each dataset. Solid (dashed) regression lines are only shown for significant trends at a $1 \%(5 \%)$ level, according to the Mann-Kendall test. The two numbers in the different panels correspond to the trends (in $\mathrm{mm} /$ year) in the periods $\mathrm{P} 1$ and P2 for the NCEP v1 series.

For the sake of comparison among zones with different precipitation amounts, the Standardized Anomaly Index (SAI) (see, e.g. Wilks, 2011) was considered rather than the original time-series for all the calculations hereafter. Therefore, trends are given in units of inter-annual observed standard deviations (STD) per year. Fig. 5 shows the GMet trends for the individual stations within each zone and for the corresponding zonal average. Small (big) dots indicate significant trends at a 5\% (1\%) level. As can be seen, decreasing (increasing) trends are predominantly found for P1 (P2) in most of the gauges and seasons. However these trends are not significant in general, except for the South and Coast zones in AMJ (the main rainy season) in $\mathrm{P} 1$. Note that, for quantitative comparison among different zones, Table 1 shows the STD of the inter-annual series of accumulated precipitation in the four zones considered for P1 and P2.

The same analysis was carried out for the different gridded products considered (Fig. 6). The result-

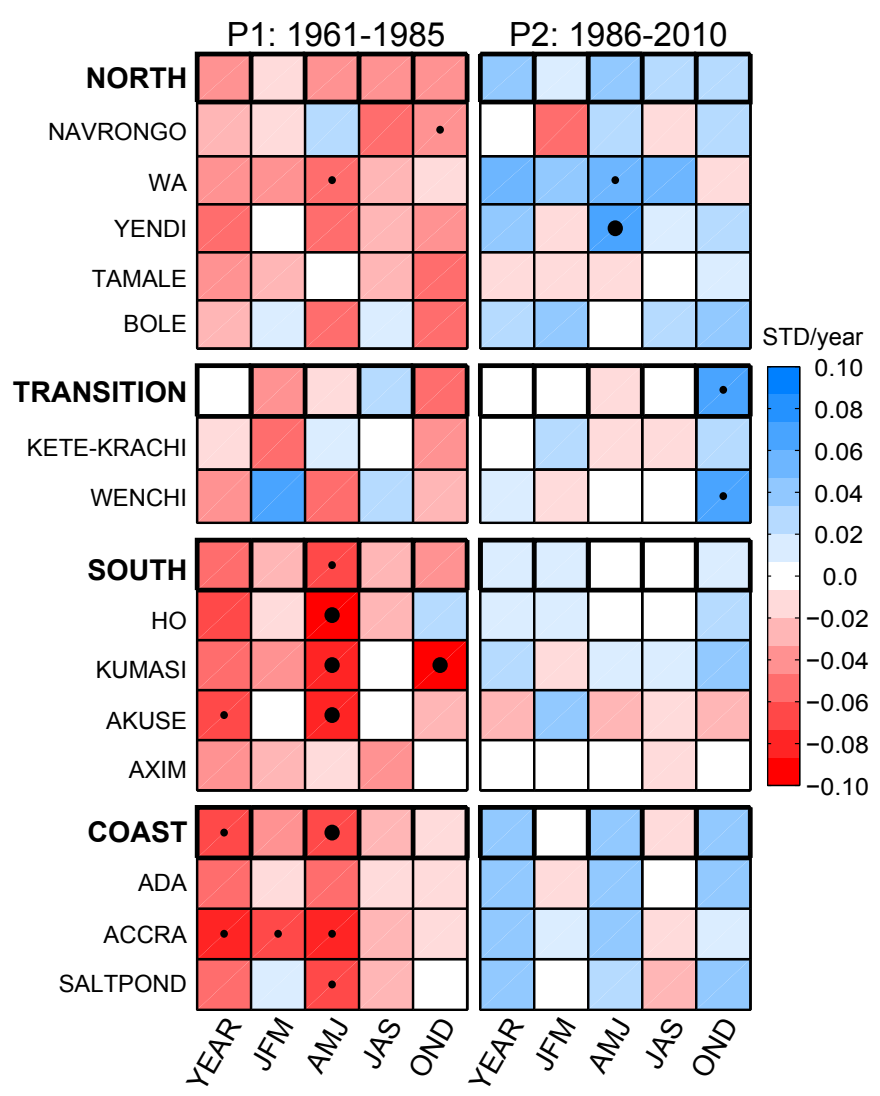

Fig. 5 Linear trends from GMet for the fourteen gauges and the four zones considered (black frames) in P1:1961-1985 (left) and P2:1986-2010 (right). Big (small) dots indicates significant trends at a $1 \%(5 \%)$ level, according to the MannKendall test.

ing trends are shown for all the reanalyses. However, given the similarities found between certain observational products, only some of them are shown for the sake of simplicity. In particular, one illustrative dataset was selected for each type of observational product, i.e., gauge-based, satellite-gauge merged and purely satellitederived. The selection was done based on the results from the performance analysis of Sec. 4.1, giving preference to those datasets showing higher correlations. Thus, in addition to TARCAT v2.0 (the only purely satellite-based product analyzed), results are shown for GPCP v2.2 and GPCC v6, in representation of the satellite-gauge merged and gauge-based products, respectively. Note that GPCP v2.2 and TARCAT v2.0 are only available for P2. However, comparing these datasets with GPCC v6 allows for assessing the effect of satellite-derived information, as it is being included in many gridded products in the last few decades.

Trends from the gauge-based products are in good and consistent agreement with observations in most of the zones and seasons - especially for P1- as shown 
Table 1 Standard deviation (STD) of the inter-annual timeseries of annual/seasonal precipitation totals for P1:19611985 and P2:1986-2010, averaged over the four zones considered. Units are $\mathrm{mm}$.

\begin{tabular}{|c|c|c|c|}
\hline Zone & Season & STD (P1) & STD (P2) \\
\hline \multirow{5}{*}{ North } & Year & 163 & 133 \\
& JFM & 28 & 19 \\
& AMJ & 53 & 57 \\
& JAS & 100 & 76 \\
& OND & 57 & 32 \\
\hline \multirow{5}{*}{ Transition } & Year & 200 & 214 \\
& JFM & 45 & 44 \\
& AMJ & 108 & 97 \\
& JAS & 132 & 121 \\
& OND & 77 & 61 \\
\hline \multirow{5}{*}{ South } & Year & 310 & 146 \\
& JFM & 53 & 42 \\
& AMJ & 131 & 90 \\
& JAS & 201 & 125 \\
& OND & 63 & 67 \\
\hline \multirow{5}{*}{ Coast } & Year & 276 & 194 \\
& JFM & 33 & 40 \\
& AMJ & 183 & 152 \\
& JAS & 145 & 103 \\
& OND & 68 & 64 \\
\hline
\end{tabular}

for GPCC v6. CRU TS 3.20 yields very similar results (not shown), which is in agreement with Harris et al. (2013), who found that previous versions of both products lead to similar results in terms of longterm trends in West Africa. Interestingly, the satellitegauge combined datasets, GPCP v2.2 and CAMS-OPI - the latter not shown - exhibit very similar trends to those from GPCC v6 for P2, whilst TARCAT v2.0, the only satellite-derived product, shows over-pronounced increasing trends, significant in some regions and seasons, what suggest than gauge-based information is needed to properly reproduce the observed trends.

In the case of the reanalyses, Fig. 6 shows that the unrealistic significant trends described for NCEP v1 in Fig. 4 are also found for ERA-40 in P1 and ERAInt in P2. On the one hand, NCEP v1 and ERA-40 lead to over-pronounced significant decreasing trends in most of the zones - especially in the North and in the Coast - and seasons in P1. On the other hand, and interestingly, NCEP v1 and ERA-Int exhibit contradictory over-pronounced significant increasing (the former) and decreasing (the latter) trends in P2. A particular interesting case illustrative of the contradictions found occurs for the North zone in JAS (the main rainy season). However, 20CR v2 shows in general no significant trends in any of the two sub-periods - except for the North zone in P1, where it is in contradiction with NCEP v1 and ERA-40) - being thus the reanalysis in better agreement with observations.

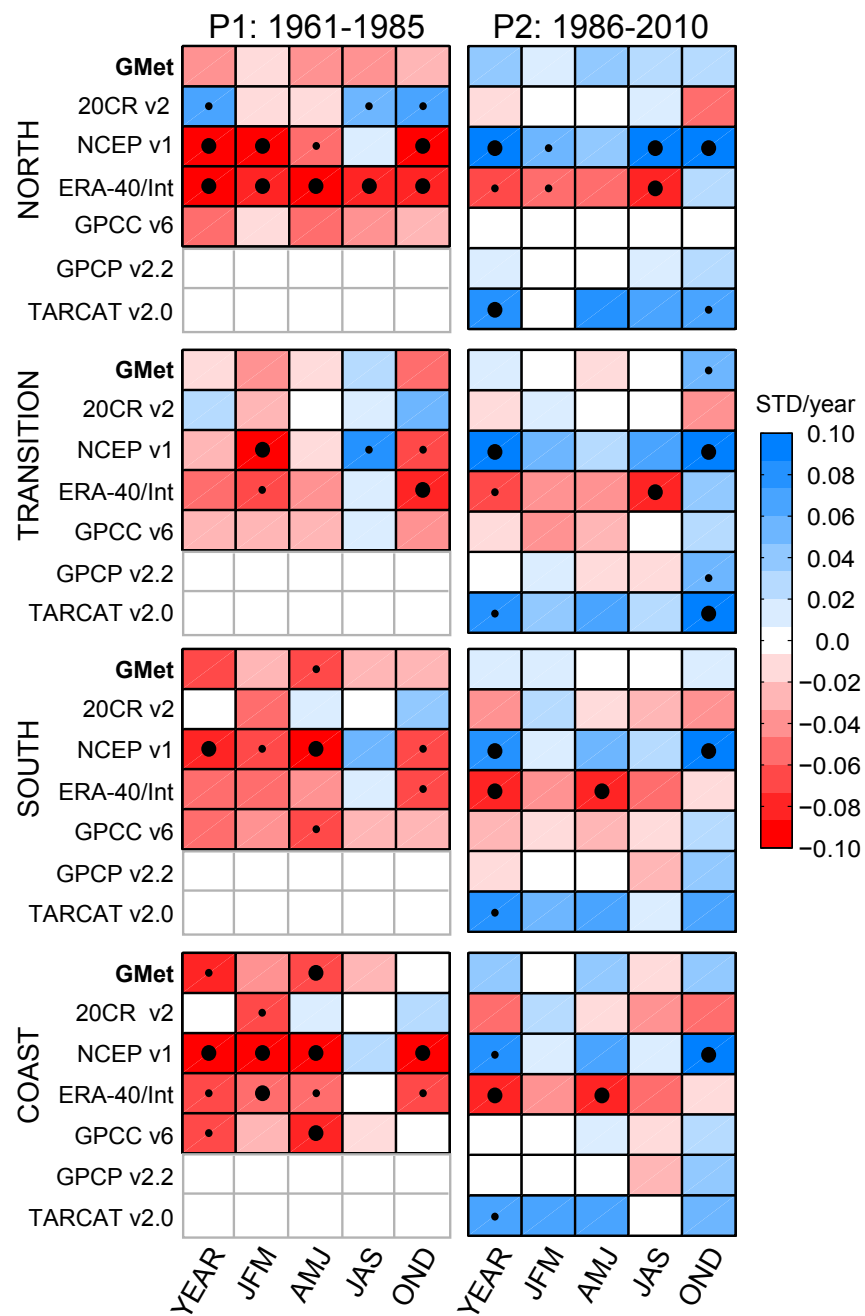

Fig. 6 As Fig. 5, but for GMet and the different gridded products considered in the four analyzed zones.

\subsection{Trends of Extreme Precipitation Indicators}

Besides the analysis of precipitation totals shown in the previous sections, we also computed several indicators to account for extreme events and spells. In particular, we selected a subset from the standard indicators recommended by the joint CCI/CLIVAR/JCOMM Expert Team (ET) on Climate Change Detection and Indices (ETCCDI), which are listed in Table 2. Note that some of these indicators have been used in previous studies (Haylock et al., 2006; Wang et al., 2006; Sillman and Roeckner, 2008).

As daily data is required for computing these indicators, only GMet and the different reanalyses were considered in this case. Trends were calculated on the inter-annual time-series of these indicators by following the same approach of the previous sections. In particular, we focus in P2 in order to check whether or not the 
Table 2 Extremes indicators analyzed (excerpt from the ETCCDI, http://etccdi.pacificclimate.org/indices.shtml).

\begin{tabular}{|c|c|c|}
\hline Indicator & Description & Units \\
\hline CDD & consecutive dry days (precipitation $<1 \mathrm{~mm})$ & day \\
CWD & consecutive wet days (precipitation $>1 \mathrm{~mm}$ ) & day \\
SDII & simple daily intensity index & $\mathrm{mm} /$ wet day \\
R10 & days with precipitation $>10 \mathrm{~mm}$ & day \\
R20 & days with precipitation $>20 \mathrm{~mm}$ & day \\
RX1DAY & maximum precipitation in 1 day & $\mathrm{mm}$ \\
RX5DAY & maximum precipitation in 5 days & $\mathrm{mm}$ \\
PRC90,95,99 & 90,95 and 99th percentile & $\mathrm{mm}$ \\
\hline
\end{tabular}

same deficiencies and contradictions found in Sec. 4.2 for some of the reanalyses hold for the case of extremes.

Fig. 7 shows the trends for six of the indices considered: CDD, CWD, SDII, R10, RX1DAY and PRC95 (similar conclusions were obtained for R10 and R20, RX1DAY and RX5DAY and for PRC90, PRC95 and PRC99, as defined in Table 2). Note that trends are now given in units of the corresponding indicator.

As can be seen, GMet trends are not significant in general and exhibit a higher zonal and seasonal variability than those obtained for precipitation totals, especially for the case of spell indicators. For the rest of indices, similar contradictions as those found in Sec. 4.2 were found for NCEP v1 (ERA-Int), which systematically tends to show stronger than observed significant decreasing (increasing) trends. Moreover, 20CR v2 exhibits again no significant trends - although with values far from reality - in most of the cases, being thus the reanalysis in better agreement with observations.

\section{Conclusions}

An assessment of the suitability of various gridded observational (gauge- and/or satellite-based) and reanalysis products for studies of precipitation variability and trends over Ghana was carried out. To this aim, data from a quality-controlled network of fourteen gauges from the Ghana Meteorological Agency (GMet) were used as reference for the period 1961-2010.

Firstly, reanalyses were shown to exhibit very poor agreement with observations, with weaker correlations - below 0.4 in most of the cases - and larger biases than any of the observational datasets considered. Among the latter, products based on gauge data showed correlations of up to 0.9 and nearly null biases, whilst those including satellite information were shown to perform slightly worse.

Secondly, a linear regression analysis for the first (1961-1985) and second (1986-2010) half of the period of study revealed the existence of predominant decreasing (increasing) trends in the GMet data. When the same analysis was performed on the gridded products, different results came out: On the one hand, trends from gauge-based and satellite-gauge merged datasets were in consistent agreement with GMet, whilst purely satellite-based datasets showed over-pronounced trends, what suggests than gauge data is needed to properly reproduce the observed trends. On the other hand, reanalyses lead often to unrealistic stronger than observed trends. Moreover, contradictory results (trends of opposite sign) were systematically found for some of them. Furthermore, the latter inconsistencies were also found for the analysis of trends of extreme precipitation indicators.

In the light of the previous results, this paper warns on the use of reanalyses for climate-related studies in Ghana since they show serious limitations for reproducing the observed inter-annual variability and trends. In particular, the performance of dynamical climate simulations over this region should be assessed with caution, since Regional Climate Models (RCMs) could be being driven by unrealistic forcings, not simulating thus properly the observed climatology (see e.g. Paeth et al., 2005). Contrarily, observational products are shown to perform reasonably well - being purely satellite-derived products the less recommendable option for reproducing over-pronounced trends.-

Note that although further validation studies are still needed (they will be feasible as precipitation series from satellite-data and from automatic weather stations become longer), this study has useful implications for the country's rain-fed agriculture, the water resources management and the energy sector, which are directly linked to food security and many socio-economic activities.

Acknowledgements This study was supported by the EU project QWeCI (Quantifying Weather and Climate Impacts on health in developing countries), funded by the European Commission Seventh Framework Research Programme under the grant agreement 243964. Additionally, the authors are very thankful to GMet (especially to Mr. Charles Yorke) for providing the gauge data. L. K. Amekudzi is also grateful to the Abdus Salam International Centre for Theoretical Physics 


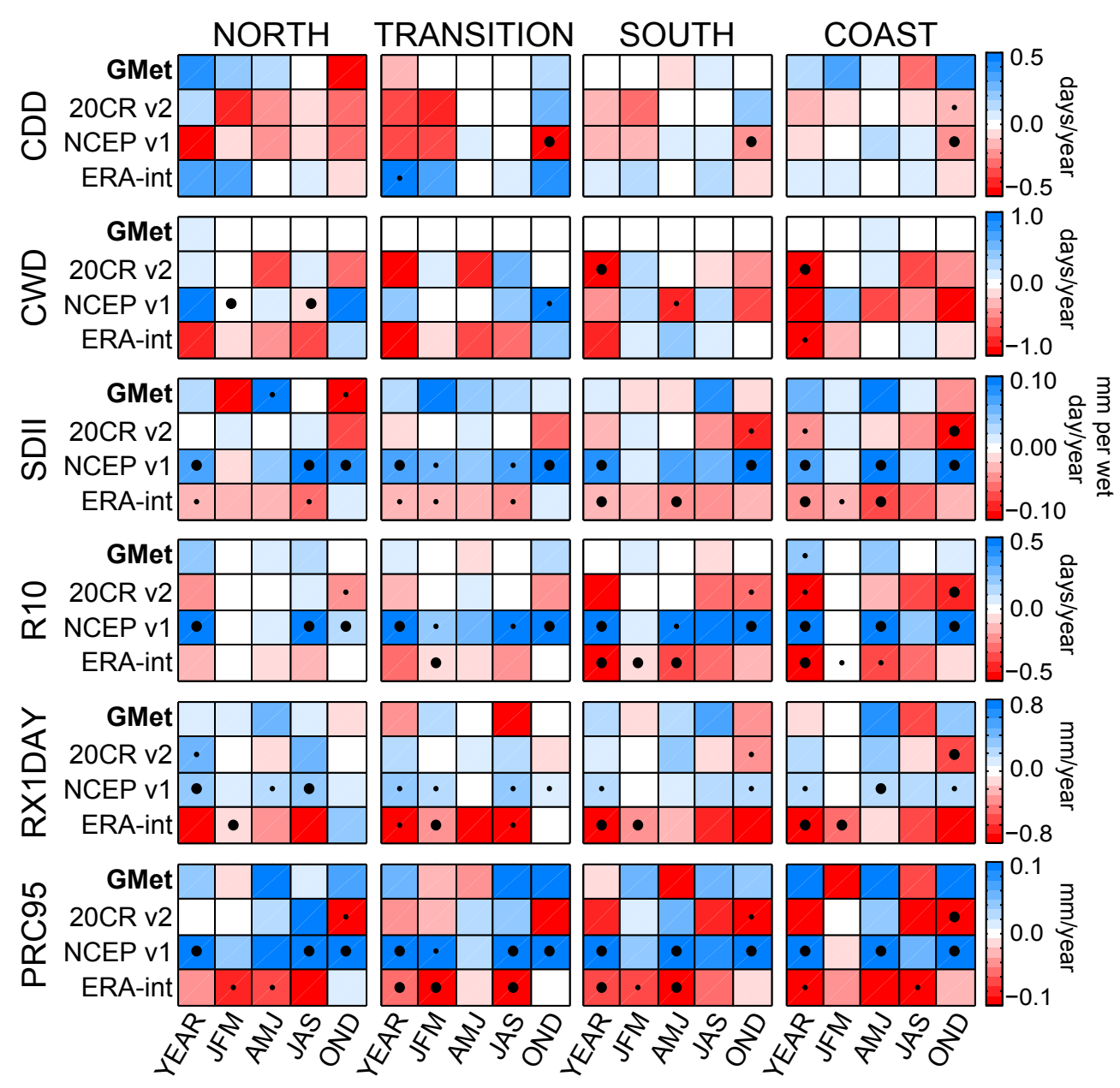

Fig. 7 Linear trends on extreme precipitation indicators (in rows) from GMet, 20CR v2, NCEP v1 and ERA-Int for the four zones considered in the period P2:1986-2010. Big (small) dots indicates significant trends at a $1 \%$ (5\%) level, according to the Mann-Kendall test.

(ICTP) for granting a sixty-six days research fellow visit including the use of its facilities. Finally, the authors want to thank the three anonymous reviewers for their detailed comments which have greatly helped to improve the manuscript.

\section{References}

Acheampong PK (1982) Rainfall anomaly along the coast of Ghana: Its nature and causes. Physical Geography 64(3-4):199-211

Becker A, Finger P, Meyer-Christoffer A, Rudolf B, Schamm K, Schneider U, Ziese M (2013) A description of the global land-surface precipitation data products of the Global Precipitation Climatology Centre with sample applications including centennial (trend) analysis from 1901present. Earth System Science Data 5(1):71-99

van Belle G, Hughes JP (1984) Nonparametric Tests for Trend in Water Quality. Water Resources Research

\section{0(1):127-136}

Burn DH, Hag Elnur MA (2002) Detection of hydrologic trends and variability. Journal of Hydrology 255(14):107-122

Chen M, Xie P, Janowiak JE, Arkin PA (2002) Global Land Precipitation: A 50-yr Monthly Analysis Based on Gauge Observations. Journal of Hydrometeorology 03(03):249-266

Compo GP, Whitaker JS, Sardeshmukh PD, Matsui $\mathrm{N}$, Allan RJ, Yin X, Gleason BE, Vose RS, Rutledge G, Bessemoulin P, BroNnimann S, Brunet M, Crouthamel RI, Grant AN, Groisman PY, Jones PD, Kruk MC, Kruger AC, Marshall GJ, Maugeri M, Mok HY, Nordli O, Ross TF, Trigo RM, Wang XL, Woodruff SD, Worley SJ (2011) The Twentieth Century Reanalysis Project. Quarterly Journal of the Royal Meteorological Society 137(654):1-28

Cooper PJM, Dimes J, Rao KPC, Shapiro B, Shiferaw B, Twomlow S (2008) Coping better with current cli- 
matic variability in the rain-fedfarming systems of sub-Saharan Africa: An essential first step in adapting to future climate change? Agriculture, Ecosystems and Environment 126:24-35

Dee DP, Uppala SM, Simmons AJ, Berrisford P, Poli P, Kobayashi S, Andrae U, Balmaseda MA, Balsamo G, Bauer P, Bechtold P, Beljaars ACM, van de Berg L, Bidlot J, Bormann N, Delsol C, Dragani R, Fuentes M, Geer AJ, Haimberger L, Healy SB, Hersbach H, Hlm EV, Isaksen L, Kllberg P, Khler M, Matricardi M, McNally AP, Monge-Sanz BM, Morcrette JJ, Park BK, Peubey C, de Rosnay P, Tavolato C, Thpaut JN, Vitart F (2011) The ERA-Interim reanalysis: configuration and performance of the data assimilation system. Quarterly Journal of the Royal Meteorological Society 137(656):553-597

Djomou ZY, Monkam D, Lenouo A (2009) Spatial variability of rainfall regions in West Africa during the 20th century. Atmospheric Science Letters 10(1):9-13

Harris I, Jones PD, Osborn TJ, Lister DH (2013) Updated high-resolution grids of monthly climatic observations the CRU TS3.10 Dataset. International Journal of Climatology pp $\mathrm{n} / \mathrm{a}-\mathrm{n} / \mathrm{a}$

Haylock MR, Peterson TC, Alves LM, Ambrizzi T, Anunciao YMT, Baez J, Barros VR, Berlato MA, Bidegain M, Coronel G, Corradi V, García VJ, Grimm AM, Karoly D, Marengo JA, Marino MB, Moncunill DF, Nechet D, Quintana J, Rebello E, Rusticucci M, Santos JL, Trebejo I, Vincent LA (2006) Trends in Total and Extreme South American Rainfall in 19602000 and Links with Sea Surface Temperature. Journal of Climate 19(8):1490-1512

Huffman GJ, Adler RF, Chang A, Ferraro R, Gruber A, McNab A, Rudolf B, Schneider U (1997) The Global Precipitation Climatology Project (GPCP) Combined Precipitation Dataset. Bulletin of the American Meteorological Society 78(1):5-20

Janowiak JE (1999) CAMS-OPI: A global satelliterain gauge merged product for real-time precipitation monitoring applications. Journal of Climate 12(11):3335-3342

Jury MR (2013) A return to wet conditions over Africa: 19952010. Theoretical and Applied Climatology $111(3-4): 471-481$

Kalnay E, Kanamitsu M, Kistler R, Collins W, Deaven D, Gandin L, Iredell M, Saha S, White G, Woollen J, Zhu Y, Leetmaa A, Reynolds R, Chelliah M, Ebisuzaki W, Higgins W, Janowiak J, Mo KC, Ropelewski C, Wang J, Jenne R, Joseph D (1996) The NCEP/NCAR 40-year Reanalysis Project. Bulletin of the American Meteorological Society 77(3):437470
Kunstmann H, Jung G (2005) Impact of regional climate change on water availability in the Volta basin of West Africa. In: Regional Hydrological Impact of Climate Variability and Change, IAHS Scientific Assembly, IAHS, 7, vol 295, pp 1-11

Lacombe G, McCartney M, Forkuor G (2012) Drying climate in Ghana over the period 1960-2005: Evidence from the resampling-based Mann-Kendall test at local and regional levels. Hydrological Sciences Journal 57(8):1594-1609

Maidment R, Grimes D, Tarnavsky E, Allan R, Stringer M, Hewison T, Roebelling R (2013) Development of the 30-year TAMSAT African Rainfall Time Series And Climatology (TARCAT) Dataset Part II: constructing a temporally homogeneous rainfall dataset. Submitted to Journal of Applied Meteorology and Climatology (8 May 2013)

Nicholson SE, Some B, Kone B (2000) An Analysis of Recent Rainfall Conditions in West Africa, including the Rainy Seasons of the 1997 El Niño and the 1998 La Niña Years. Journal of Climate 13(14):2628-2640 Novella NS, Thiaw WM (2013) African Rainfall Climatology Version 2 for Famine Early Warning Systems. Journal of Applied Meteorology and Climatology 52(03):588-606

Obot NI, Chendo MAC, Udo SO, Ewona IO (2010) Evaluation of rainfall trends in Nigeria for 30 years (1978-2007). International Journal of Physical Sciences 5(14):2217-2222

Ofori-Sarpong E (2001) Impact of climate change on agriculture and farmers coping strategies in the upper East region of Ghana. West African Journal of Applied Ecology 2

Owusu K, Waylen PR (2009) Trends in spatio-temporal variability in annual rainfall in Ghana (1951-2000). Weather 64(5):115-120

Owusu K, Waylen PR (2013) The changing rainy season climatology of mid-Ghana. Theoretical and Applied Climatology 112(3-4):419-430

Paeth H, Born K, Podzun R, Jacob D (2005) Regional dynamical downscaling over West Africa: Model evaluation and comparison of wet and dry years. Meteorologische Zeitschrift 14(3):349-367

Partal T, Kahya E (2006) Trend analysis in Turkish precipitation data. Hydrological Processes 20(9):20112026

Sillman J, Roeckner R (2008) Indices for extreme events in projections of anthropogenic climate change. Climatic Change 86:83-104

Sultan B, Janicot S (2003) The West African Monsoon Dynamics Part II: Preonset and Onset of the Summer Monsoon. Journal of Climate 16(21):3407-3427 
Tarnavsky E, Grimes D, Maidment R, Stringer M, Chadwick R, Allan R (2013) Development of the 30-year TAMSAT African Rainfall Time Series And Climatology (TARCAT) Dataset Part I: improved calibration and operational validation. Submitted to Journal of Applied Meteorology and Climatology (8 May 2013)

Uppala SM, Kllberg PW, Simmons AJ, Andrae U, Bechtold VDC, Fiorino M, Gibson JK, Haseler J, Hernandez A, Kelly GA, Li X, Onogi K, Saarinen S, Sokka N, Allan RP, Andersson E, Arpe K, Balmaseda MA, Beljaars ACM, Berg LVD, Bidlot J, Bormann N, Caires S, Chevallier F, Dethof A, Dragosavac M, Fisher M, Fuentes M, Hagemann S, Hlm E, Hoskins BJ, Isaksen L, Janssen PAEM, Jenne R, Mcnally AP, Mahfouf JF, Morcrette JJ, Rayner NA, Saunders RW, Simon P, Sterl A, Trenberth KE, Untch A, Vasiljevic D, Viterbo P, Woollen J (2005) The ERA-40 re-analysis. Quarterly Journal of the Royal Meteorological Society 131(612):2961-3012

Wang B, Ding Q, Jhun JG (2006) Trends in Seoul (17782004) summer precipitation. Geophysical Research Letters 33(15):n/a-n/a

Wilks DS (2011) Chapter 3 - Empirical distributions and exploratory data analysis. In: Statistical methods in the atmospheric sciences, International Geophysics, vol 100, Academic Press, pp $23-70$

Xie P, Arkin PA (1997) Global Precipitation: A 17Year Monthly Analysis Based on Gauge Observations, Satellite Estimates, and Numerical Model Outputs. Bulletin of the American Meteorological Society 78(11):2539-2558

Zhang X, Harvey KD, Hogg WD, Yuzyk TR (2001) Trends in Canadian streamflow. Water Resources Research 37(4):987-998 